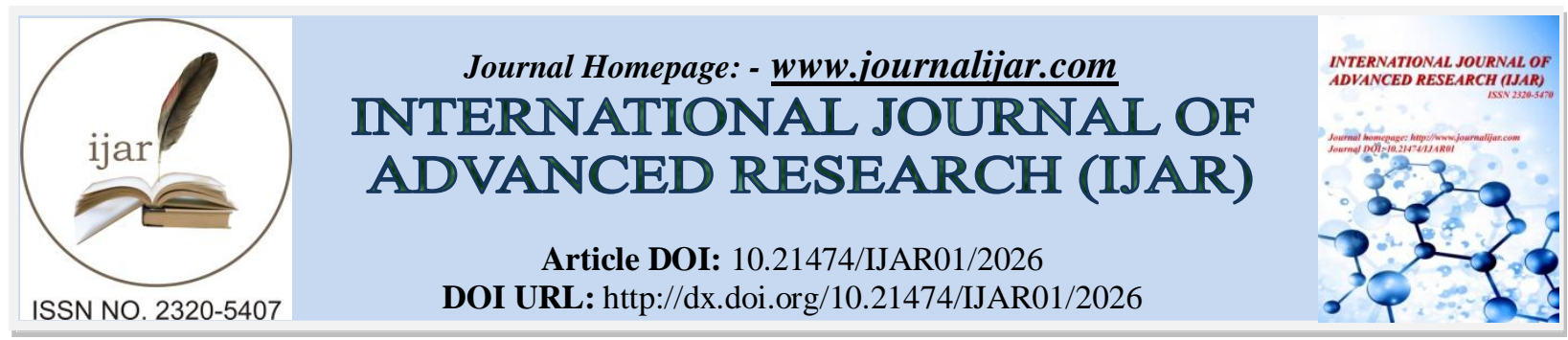

RESEARCH ARTICLE

\title{
MAIN ASPECTS OF HOSPITAL DENTISTRY: REVIEW OF ITS IMPORTANCE.
}

Bruno Afonso Cortez Martinez ${ }^{1}$, Fernando Coelho Fidelis ${ }^{1}$, Lorrayne Fernandes Mastrocolla ${ }^{1}$, Taylane Soffener Berlanga de Araujo ${ }^{1,2}$, Fabio Pereira Linhares de Castro, ${ }^{1,2}$, Ana Paula Bernardes da Rosa Maluf Abbud ${ }^{1,2}$, Leandro Moreira Tempest ${ }^{1}$, Elias Naim Kassis ${ }^{1,2}$ and Idiberto José Zotarelli Filho ${ }^{2}$.

1. University Center North Paulista (Unorp) - São José do Rio Preto - SP, Brazil.

2. Post graduateandcontinuingeducation (Unipos), Street Ipiranga, 3460, São José do Rio Preto SP, Brazil 15020040 .

\section{Manuscript Info}

[.........................

Manuscript History

Received: 25 September 2016

Final Accepted: 9 October 2016

Published: October 2016

Key words:-

Hospital Dentistry; Dental Surgeon;

Multidisciplinarity.

\section{Abstract}

Medicine and dentistry are united mainly with patients hospitalized in poor health, to determine how best to act on oral health, and aimed at improving the patient's overall health and quality of life. The objective of this study was to present the importance of Hospital Dentistry, so that in the near future will be recognized by all classes, and especially in hospitals that they may be aware of how important is the presence of a dental surgeon in the hospital. In methodology for the identification of literary findings on hospital dentistry of this review, a detailed search strategy was conducted for Medline (Pubmed), Scielo and Bireme in the years 2002-2016, as well as books and magazines related the theme. In the literature review we noted that the insertion of the dental surgeon in the hospital environment is little known, and when, is linked to specialty Oral and Maxillofacial Surgery. In the team for the execution of activities in addition to specialized dentists, technicians prosthesis, dental assistant, auxiliary and / or nursing administrative and technical staff, it is important that everyone knows the dental and hospital routine. It was concluded that the inclusion of dentists in the hospital routine is incipient and is linked to specialty Surgery and Traumatology Buco Maxillofacial. So that it becomes routine hospital treatment with a focus on prevention and improvement in the clinical picture of the patient, you have to educate the authorities and health professionals about their importance in multidisciplinary teams.

Copy Right, IJAR, 2016,. All rights reserved.

\section{Introduction:-}

Has witnessed great emphasis in the area of medical science in almost all areas and this has benefited the general health of patients [1]. These advances have improved the technology area, the pharmaceutical industry and various progress in most areas of treatment and medical procedures [8]. The growth of medicine has benefited patients of all ages, from fetuses older, running any type of surgical procedure being he or treatment $[2,21]$. 
Medicine and Dentistry are struggling mainly with patients hospitalized in poor health, to determine how best to act on oral health, and aimed at improving the patient's overall health and quality of life [1], [2-5]. This care has to be synchronized between doctors and dentists, carefully [21].

The practice of providing oral health care to patients hospitalized with impaired general health, often referred to as "Oral Medicine", is not a novel concept [3-6]. However, clearly it had a significant boost over the last 10 years [9]. oral health professionals around the world are striving for greater involvement of specialists in this area in the hospital. However, enthusiasm for progress in this area faces several major challenges and critical [12].

Among them, the most worrying: what if doctors and surgeons suddenly and unanimously recognize and accept the importance of oral health care as part of the treatment of their patients and try to incorporate oral hygiene care in hospital protocols [13]. Few problems could be more devastating to the advancement of the role of oral medicine in the hospital if there was a universal demand for qualified professionals in oral medicine to care for patients in the hospital, but did not have an adequate number of these trained and able to provide necessary assistance to the patients $[2,21]$.

It is extremely important that it is used a high level of training based on evidence, the training of dentists is important to have on your resume knowledge of oral medicine to thus improve the clinical experience of oral medicine in hospital settings [21]. The Hospital Dentistry is the area of general dentist or specialist working in a hospital environment, performing low procedures, medium or high complexity and may be in hospitalized patients or not, leading to cure or improvement of quality of life, and which is the kind of disease of this patient [14].

There is an initial tendency to relate the dentists who work in Hospital Dentistry with existing specialty dedicated especially to the Oral and Maxillofacial Surgery and Dentistry for patients with special needs. [17] It is important to note that much of the professionals working in $\mathrm{OH}$ branch has links to these specialties, but is not required for those who want to act in the world of $\mathrm{OH}$ to be an expert in the mentioned areas, but knowledge and experience in this field [23]. The presence of the dentist in the hospital is not only related to surgery, but several areas of dentistry, and oral rehabilitation, diagnosis of oral diseases, emergency procedures and interpretation of additional tests [11].

Thus, dentistry is indispensable in the hospital, whether general or specialties in various situations in the case of diagnosing the oral cavity disease or systemic diseases with oral findings. Specific treatments of diseases of the oral cavity and attachments, as well as assist in the treatment of general diseases. Little is disclosed about the impact oral health and its correlation with systemic health and vice versa [1,2].

It should be noted that dental procedures in the hospital environment extend beyond those used in patients with special needs or with a physical disability, mental, emotional and medical condition which precludes the service in the dental office. [11] The dentist also works in multidisciplinary teams especially in the hospital, which is mandatory when the ultimate goal is to improve the quality of life of patients. Why the CD has to be trained for this type of care in the hospital, because not part of their training [1,11].

The first full Hospital Dental Service was in Philadelphia (USA) in 1901, John Shoemaker realized that hospital patients needed dental care. Already in 1945 Harry Archer in Philadelphia, was concerned about the lack of care [2,3]. In addition, in 1938, the American Dental Association and the Canadian Dental Association, supported the Hospital Dentistry, which was recognized and respected community of hospital health workers [3,4].

In Brazil it is difficult to know precisely where and when the hospital dentistry had its beginning, for lack of documented information, but we can say that had much effort of professionals and institutions that the need sought excellence in care of the oral health of patients in hospitals, several centers simultaneously, ie in the middle of the twentieth century. [5] In the early twenty-first century, the National Council of Dentistry of São Paulo (CROSP) and the Paulista Association of Dentists (APCD), mobilized for the development of hospital dentistry. [5]

In Dental Code of Ethics is contemplated Hospital Dentistry in Chapter IX, Article 18, citing that it is for CD intern and assist patients in public and private hospitals with and without philanthropic, subject to the administrative technical rules of the institutions. Next, Article 19 provides that the activities carried out in dental hospitals will obey the rules of the Federal Council. Finally Article 20 provides that constitutes ethical breach, even in a hospital setting, perform surgery outside the scope of dentistry. Thus the Hospital Dentistry should always draw new goals 
and higher goals such as teaching and research, standardization of operation of public and private policy initiatives order for the professional class of Hospital Dentistry have greater recognition [5].

The objective of this study was to present the importance of Hospital Dentistry, so that in the near future will be recognized by all classes, and especially in hospitals that they may be aware of how important is the presence of a dental surgeon in the hospital . It is hypothesized that the Hospital Dentistry improve the quality of life mostly hospitalized patients, bringing healing and clinical improvement, to reduce the risk of more serious diseases that can be acquired due to lack of oral health.

\section{Methods:-}

For the identification of studies in this review study, carried out a detailed search strategy for Medline, Pubmed, Embase, Ovid and Cochrane Library in the years 2002 - 2016, as well as books and related to the topic magazines. They were used the descriptors: "hospital dentistry", "incidence and prevalence", "historic", "dentist","multidisciplinary". Analyzed studies systematic review, meta-analysis, randomized controlled cases, nonrandomized clinical cases and opinion articles que Addressed the term atraumatic surgery. The date wereanalyzed, correlated to the discussion of the results highlighted in the literature, the shown in graphic 1.

\section{Literature Review:-}

The definition of Dentistry hos ppitalar according to Camargo (2011) [5] is a practice that seeks care of oral alterações procedures that require multidisciplinary teams of highly complex patient. When it comes to an integrated Dentistry to a multidisciplinary team should treat the individual as a whole, not only focus on the oral cavity region, because the mouth is home to micro-organis $\neg$ mos that easily win the current circulatory exposing the patient to a risk of a disease [1].

Dentistry cannot be isolated from other professions but compartilhar their responsibility with other health professionals as the doctor, with emphasis on surgery and the prophylaxis pre and postoperative. From the beginning, the practice of the health professions was to diagnosticar goal and promote the treatment of diseases. The expressão "art of healing" everyone used to say assigned to the medical profession explains this approach $[2,3]$.

Because of prejudice related to dental practice in the hospital, there is a difficulty to the comprehensive care of the patient. This makes the dentists performing their work only in offices and public health clinics, except for cases of bucomaxilofacial surgery or procedures that require general anesthesia. Many health professionals do not know or have information as to the relevance of the dentist acting in the hospital. In most cases unfortunately these professionals do not know why the dentist is in a hospital [4].

The Oral and Maxillofacial Surgery for idealistic construction of Hospital Dentistry, and the "umbilical cord" of the work of dentistry surgeons in hospitals, taking care of injured patients in transit or falls, wounded with a firearm and patients suffering from beatings, in short, facial trauma. So this is one of Odontologia specialties more established within the hospitals, although some barriers still need to be addressed [10].

In the hospital setting are not performed only approaches surgicalsalso covers the training and supervision of hospitalized patients for manutention oral health and preventing disease, promoting hygiene and constant inspection of the mouth and associated structures [1,2]. In the hospital environment, the hospitalized patient should be monitored and dentists have fundamental role in the assessment of oral health, reinforcing the idea that these assessments are essential for the care of the overall health and patient care as a whole [14].

In the sixteenth century in Brazil, dental problems were treated by so-called "barbers," they were outdoor procedures in fathoms, markets. In the eighteenth century, they began to lose ground to professionals, thus the calls began to be made in their homes dentists, called the first offices. In the twentieth century we had a whole evolution in the field of scientific technical health, particularly in dentistry, but even so the dentist was isolated in their private offices, with almost no involvement with other health professionals. [15]

This type of operation has changed, following the changes in the dissemination and new techniques developed. As medicine has advanced in the areas of diagnosis and treatment, thus had improved quality of life of patients with chronic diseases [2]. Thus, diseases that were fatal, along with preventive action, captured the increase in population 
life expectancy, and the isolation of the professional is not feasible. With these changes in the labor market, with the government recognition of the need for oral health in several areas, it gives the opportunity for professionals to seek new fields, such as hospital care [16].

The insertion of the dental surgeon in the hospital environment is little known, and when, is linked to specialty Surgery and Traumatology Buco Maxillofacial [1]. To become something routine in hospitals with the focus of prevention and improvement in the clinical picture of the patient, you have to educate the authorities and health professionals about their importance in multidisciplinary teams, and the work becomes effective, it is necessary knowledge of the hospital's needs being inserted, as well as within the hospital environment [18].

In the team for the execution of activities in addition to specialized dentists, technicians prosthesis, dental assistant, auxiliary and / or nursing administrative and technical staff, it is important that everyone knows the dental and hospital routine [1,2]. The dentistry odontology is a field of work expanding the oral pathologies are emphasized because they are responsible for most secondary diseases in hospitalized patients. It is no longer acceptable for patients in wards and especially in ICUs, are not treated in full [2]. Thus, interdisciplinarity is the attempt to establish relationships between the disciplines, all professionals of health who work in hospitals should be aware and able to play both multidisciplinary as interdisciplinarity.

\section{Intensive Care Units Dentistry:-}

It is believed the relationship between oral and systemic diseases is a fact proven by several studies, and, the first citations occurred in the late seventeenth century gradually evolving until the present day. From these studies it was shown that oral problems, especially periodontal disease, can act as a focus for dissemination of pathogens with systemic metastatic effect, especially in people with compromised health, such as hospitalized in ICUs [5].

In the oral environment, there is the presence of hard surfaces, no scaling, such as enamel, dentin, restorations, prostheses, implants, among others, promoting the onset and buildup of bacterial plaque. The board also known as biofilm is the main cause of oral diseases [19]. Through the bacterial metabolism, the biofilm is capable of producing irritants such as acids, endotoxins and antigens that, with time, dissolve the teeth and destroy the supporting tissues, so it is considered the main reason for the establishment of caries disease periodontal and stomatitis. Additionally, the plaque may serve as a permanent reservoir of microorganisms causing infections distance [2].

Thus, in ICUs, it is extremely important to be monitoring of organs and systems, which are not the direct cause of the problem that caused the patient to this condition. This attention prevents deterioration of another body or system that can contribute to a poor prognosis of the case, such as stomatognatic system should receive adequate attention, since the prevalence, extent and severity of periodontal diseases is very high in the population [22].

Patients with inadequate oral hygiene and poor dental conditions present greater risk of local and systemic complications. The deficiency in oral hygiene is very common in ICU patients, possibly due to lack of appropriate techniques for intensive care teams, and the absence of inter-relationship dentistry / nursing [22].

Inadequate oral hygiene in critical patients triggers periodontitis, gingivitis, ear infections, chronic nasopharyngitis, dry mouth potential focus of infection favorable to nosocomial pneumonia. In addition, patients in ICUs remain open mouth due to tracheal intubation, allowing dehydration of the oral mucosa. This decrease in saliva flow, increased tongue biofilm, causing an unpleasant odor, as well as increases in bacterial colonies [24].

Before the bacterial risks stemmed from the oral cavity, it is important to be carring out in ICU patients, efficient cleaning in the oral tissues, including: teeth, gums and tongue; removing food debris and plaque, in order to promote a less susceptible oral environment to oral diseases. It is important to choose a product as an auxiliary method in reducing plaque [24]. Thus, studies indicate that the ideal is an enzyme product without abrasive substances in its composition, it further undermines the oral mucosa already committed, and which contains lactoferrin, which through its action and its interactions with the saliva reduces the incidence of Candida albicans and Candida krusei in the oral mucosa [24].

Thus, periodontal disease, may act as a focus for the spread of pathogenic microorganisms with systemic metastatic effect, especially for critical patients, it is believed that it is essential to dental treatment in ICUs, especially 
periodontal intervention in the prevention and / or improvement of condition systemic [5]. The health at the moment is seen from multifactorial points, treated by multidisciplinary teams, aiming the balance of the individual as a whole, not simply summarizing the absence of disease and physical well being, but also a multidimensional aspect that presents beyond the physical, but psychological and social [5].

Within the hospital setting, the presence of a multidisciplinary team can provide early diagnosis and treatment of dental disease in ICU patients. It is extremely important that there are doctors, nurses, dietitians, speech therapists, psychologists, physiotherapists, pharmacists and dentists in the treatment of critically ill patients by preventing and treating oral diseases, and preventing them from causing systemic damage to the patient. Thus, it is well evident the need for action of the Dental Surgeon as a permanent member of an effective multidisciplinary team in ICUs [24].

It is known that the main obstacle faced by dentists to integrate multidisciplinary teams in the ICU is the low priority of the dental procedure before the numerous problems presented by the patient. However, the literature is increasingly demonstrating the importance and influence of oral health in the evolution of the framework of critically ill patients [24].

Among the systemic diseases that have the greatest relationship with oral health are respiratory infections, with emphasis on pneumonia, identified as the second most responsible for hospital infections, with high rates of evolution to death. In ICUs this incidence increases with mortality can reach up to $80 \%$ of those infected. From these data it is clear the importance of introducing dentists in ICUs, since the relationship between lung infections and oral health are large, requiring the acquisition and maintenance of oral health, and greater integration of dentistry and medicine, aimed at the overall treatment of patients, the disease prevention and greater humanization of the ICU patients [15]. Pneumonia is an infection in the lung parenchyma caused by a variety of infectious agents (bacteria, mycoplasmas, fungi, parasites and viruses), bacteria are the most common causes of these infections. They are usually classified as community-acquired pneumonia and nosocomial pneumonia [15].

The nasocomial pneumonia are those developed in the hospital after 48 hours of hospitalization, not present or incubated in the patient at the time of admission to hospital. As one of the leading causes of morbidity and mortality in hospitalized individuals, and also impose high costs to the population, by increasing the length of hospital stay and increased demand therapy [15]. The establishment of nosocomial pneumonia occurs with bacterial invasion, especially Gram-negative rods (Acinetobacter spp., Staphylococcus aureus, Esherihia coli, Klebsiellaspp, Pseudomonas ae-ruginosa, Enterobacter spp., And Proteus mirabiis). These micro-organisms can infect the lower respiratory tract by this secretion aspiration of oropharyngeal aspiration esophagogastric content [15].

Some risk factors are important in the educational establishment of nasocomial pneumonia, such as patients undergoing endotracheal intubation or mechanical ventilation, patients with decreased level of consciousness, individuals who are victims of large volume secretion aspiration, poor oral condition, malnutrition, patients with heart disease or chronic lung, advanced age (patients older than 70 years), use of antibiotics, presence of gastric tube, severe trauma, recent bronchoscopy, renal failure, cancer; syndrome of acute respiratory distress, tracheostomy, patient handling by the hospital staff, tracheobronchial secretion aspiration and bronchial aspiration of oropharyngeal microorganisms [4].

Of all the risk factors, which more than stands out is the aspiration of oropharyngeal contents. The establishment of bacterial pneumonia depends oropharyngeal colonization by potential respiratory pathogens by these suction to the lower airways and also the capacity of the same escape the body's natural defenses. [4]

Although small amounts of suction secretions from the oral cavity is common in healthy individuals, especially during sleep in patients consciousness level status change often they strive larger amounts of secretions of the buccal cavity, and with greater frequency. This aspiration associated with a failure in the host defense system to eliminate infectious bacteria, favors their multiplication [4]. Thus, it is clear the importance of oral biofilm as the main contributor to respiratory infections by aspiration, since the oral cavity is the first input port for respiratory pathogens causing infections such as pneumonia nasocomial.

Thus, reduction in the number of oral microorganisms aid in the reduction of microorganisms available for colonization and infection of the lungs, since the accumulation of oral pathogens may change the environmental conditions of the mouth and facilitate infection of the airways by novel microorganisms [1,2]. After identification of 
bacteria biofilm in the oropharyngeal cavity, it is evident that there is an association between bacterial composition of dental biofilm and nasocomial pneumonia and any such settlement be favored or aggravated with oral hygiene neglected during the hospital stay of patients [5].

The presence of Dentists in multidisciplinary teams help significantly reduce the rates of nasocomiais pneumonia in ICUs, managing to not only improve the quality of oral health, but also avoid a higher incidence of cross and secondary infections, the use of the preventive process, reducing length of hospitalization of these patients and complications from it, as well as the significant reduction in costs. [15]

The evaluation of oral health and dental treatment in hospitalized patients require follow-up by a dentist qualified in Hospital Dentistry, assessing, preventing and treating the presence of biofilm, periodontal disease, tooth decay and precursor oral lesions infections, minimizing the proliferation of fungi and bacteria, which represent risk or discomfort to hospitalized patients, significantly reducing the appearance of nasocomial pneumonia and promoting the welfare of the oral health of the patient [4].

Graphic 1:- Quantitative data on the types of works found in relation to hospital odontology in five database.

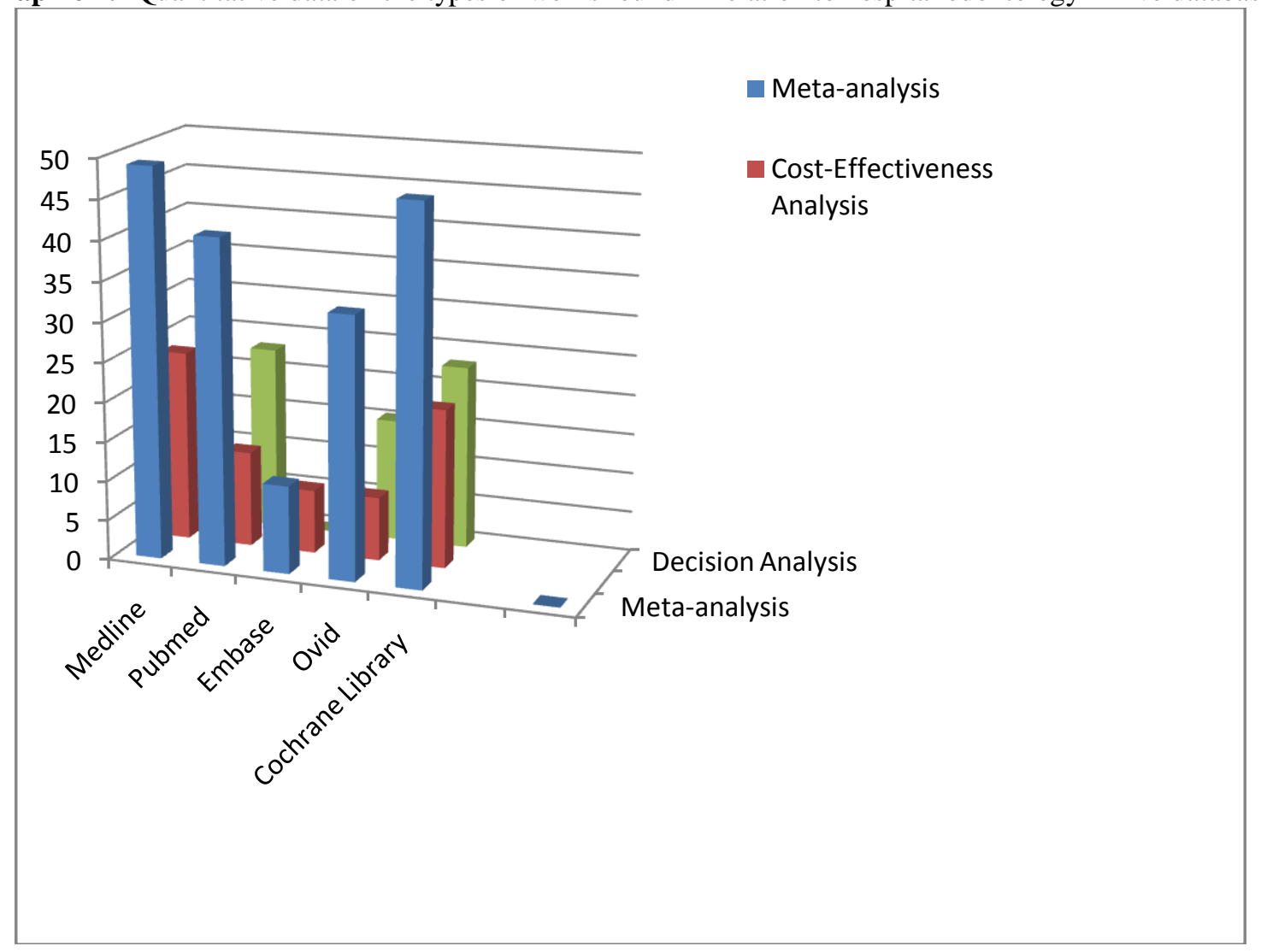

\section{Discussion:-}

The role of Dental Surgeons in hospitals can be quite comprehensive. To work in the hospital, the surgeon-dentist must, in addition to being an excellent general practitioner, understand the general diseases of the body and its etiopathogenesis as well as diagnostic and therapeutic mechanisms. Thus, within the hospital setting, the dentist may conduct admissions, interpret complementary tests and control hospital infections, acting in decreased hospital stay, and know the routines of the hospital environment, be aware of the rules and standard operating procedures and have the ability to teamwork, as demonstrated by Camargo (2011) [5].

Thus, according to Camargo (2011) [5] all that enables the health of the oral structure, contributing to the maintenance of masticatory function, breathing, speech and swallowing will result in restoring the health of the individual, contributing significantly to the reduction of patient stay in bed, in addition to reducing the morbidity of 
treatment of the underlying disease and its sequelae. The monitoring by the dentist is essential, for example, requests for specific tests and more detailed when it distrusts systemic changes in progression.

To confirm Martinelli (2011) [15] said that it is necessary to identification of infection and their removals, both surgical as clinics and acting in emergencies (pain, bleeding control and fractures), diagnosis and treatment of injuries mouth associated with systemic diseases. Such as periodontal disease because some systemic conditions can be affected by periodontal disease and periodontal disease may be influenced by certain systemic condition. In addition, some medicines may also be used risk factors for periodontal disease, as anticonvulsants, antidepressants and various drugs associated with reduced salivary flow.

These profissional important in various medical teams [1]. Groups of medical specialties commonly requested the support of dentistry are Oncology, Hematology, Cardiology, Dermatology, Psychiatry, Intensive Care, Endocrinology, Transplantation of Organs and Tissues, Neurology, Rheumatology, Infectious Diseases and Nephrology [2]. In dermatology, for example, it helps in the diagnosis and treatment of oral manifestations, as in psychiatry, its comtribuição is related to improvement in pain and aesthetics of the patient, factors that may contribute to the imbalance of the psychic apparatus of an individual. Moreover, persons with congenital or acquired imunode fi sciences must be constantly observed and treated foci compared to oral infection and sequelae such as xerostomia and autoimmune disease [3].

According to Martinelli (2011) [15], epidemiological studies have provided strong evidence of the role of moderate periodontal disease severe as a risk factor to the overall health of the individual, including cardiovascular disorders, stroke, diabetic metabolic decontrol, lung infections and premature birth. In this context, it is also extremely important that patients undergoing cardiac surgery or stem cell transplantation hematopoietic and solid organs are examined by Dentists preoperatively. The plaque also known as biofilm is considered the main cause of oral diseases. In this biofilm are the Streptococci bacteria, Actinomyces, actinomycetemcomitans, Eikenella, Fusobacterium, Porphyromonas, and Treponema [3-5].

Studies by Lemos; Villora (2008) [14] indicate that Tanerellaforsythensis (formerly - Bacteroidesforsythus) Porphiromonasgingivalis and A. actinomycetemcomitans are considered responsible for most of the gingival and periodontal infections, and Streptococcus mutans responsible for dental caries. The performance of the bacterial agent will depend on factors such as length of stay, use of antimicrobials, type of ventilation and nutrition, control of oral hygiene, oral diseases and systemic present, in addition to the ICU microbiota susceptibility.

Infection is a common complication and high mortality in patients admitted to intensive care unit. It is extremely important that there is a concern with oral infections, as they can become the primary focus of systemic infections in ICU patients. Measures to reduce the oral source of infection outbreaks ranging from care and local sanitization techniques like search products that assist in the homeostasis of the oral environment and in reducing bacterial flora [1-3].

Importantly respiratory pathogens originating from among hospital environment can colonize the surfaces of teeth, dentures, oral mucosa and its biofilm. The establishment of exogenous respiratory pathogens such surfaces may be facilitated by partial reduction, or total salivation and saliva $\mathrm{pH}$ [5]. A concomitant inadequate oral hygiene the use of drugs, will change salivation capacity, as well as its $\mathrm{pH}$, increasing the amount of bacteria in the oral biofilm. These bacteria release enzymes that alter the chemistry of the oral surface of the patient, thereby increasing the adhesion and colonization by respiratory pathogens $[2,5]$.

In this context, it endende that dental care to hospitalized patients with systemic diseases effectively contributes to their recovery. Dentistry in maintaining oral health of patients in ICUs because improved systemic condition of the patient, preventing increased proliferation of fungi and bacteria and resulting infection, especially nasocomiais infections [2].

\section{Conclusion:-}

It was concluded that the inclusion of dentists in the hospital routine is incipient and is linked to specialty Surgery and Traumatology Buco-Maxillofacial, requiring expansion in care, such as inhibition of infectious processes. 


\section{Competing Interests:-}

The authors declare que they have no competing interests.

\section{References:-}

1. Rubio MC, Lewin PG, De la Cruz G, Sarudiansky AN, Nieto M, Costa OR, Nicolosi LN. Effect of angiotensinconverting enzyme inhibitors on vascular endothelial function in hypertensive patients after intensive periodontal treatment. ActaOdontolLatinoam. 2016; 29(1):60-67.

2. Kreiner M, Álvarez R, Michelis V, Waldenström A, Isberg A. Craniofacial pain can be the sole prodromal symptom of an acute myocardial infarction: an interdisciplinary study. ActaOdontolLatinoam. 2016; 29(1):2328.

3. Baum, B. J. Inadequate training in the biological sciences and medicine for dental students. J. Am. Dent. Assoc.; 138 (1): 16-25, 2007.

4. Beikler, T., Flemmig, T. F. Oral biofilm-associated diseases: trends and implications for quality of life, systemic healthy and expenditures. Periodontol. 2000. 55 (1): 87-103, 2011.

5. Camargo, E. C. Odontologia Hospitalar é mais do que Cirurgia Bucomaxilofacial. Acesso em: 19/07/2011. Disponível em: http://www. jornaldosite.com.br/arquivo/anteriores/elainecamargo/artelainecamargo98.htm, 2011.

6. Chandra, R. V. Medicine for dental students. J. Am. Dent. Assoc; 138 (4): 436-8, 2007.

7. Doro, G. M. Hospital dentistry Project. Rev. Abeno; 6 (1): 49-53, 2006.

8. Feijó, R. D.; Coutinho, A. P. Manual de prevenção de infecções hospitalares do trato respiratório. 2nd ed. São Paulo: Associação Paulista de Estudos e Controle de Infecção Hospitalar; 2005.

9. Galvão, C. M. A prática baseada em evidências: uma contribuição para a melhoria da assistência de enfermagem perioperatória [thesis]. RibeirãoPreto: Universidade de São Paulo; 2002.

10. Glassman, P, Caputo, A, Dougherty, N.Special Care Dentistry Association consensus statement on sedation, anesthesia, and alternative techniques for people with special needs. Spec. Care Dentist.; 29 (1): 67-8, 2009.

11. Godoi, APT., Francesco, AR., Duarte, A. Odontologia hospitalar no Brasil. Uma visão geral. Rev. Odontol. Unesp; 38 (2): 105-9, 2009.

12. Gusmão, ME.; Dourado, I, Fiaccone, RL. Nosocomial pneumonia in the intensive care unit of a Brazilian university hospital: an analysis of the time span from admission to disease onset. Am. J. Infect. Control., v. 32, n. 4, p. 209-14, 2004.

13. Koeman, M.; Van Der Ven, AJ, Hak, E. Oral decontamination with chlorhexidine reduces the incidence of ventilator-associated pneumonia.Am. J. Respir. Crit. Care Med., v. 173, n. 12, p. 1348-55, 2006.

14. Lemos Junior, CA, Villora, GEM. Revisão das evidências sobre a segurança do uso diário de enxaguatórios bucais à base de álcool. Braz. oral Res., v. 22, n. 1, p. 24-31, 2008.

15. Martinelli, M. O. Real sentido da Odontologia hospitalar. Acesso em: 16/06/2011. Disponível em: http://abraoh.com.br//publicacoes/.

16. Meira, SCR, Oliveira, CAS, Ramos, IJM. A importância da participação do cirurgião-dentista na equipe multiprofissional hospitalar. Trabalho vencedor na $9^{\circ}$ edição do prêmio SINOG de Odontologia 2010. Curso de Odontologia do Centro Universitário Newton Paiva, Belo Horizonte/MG.

17. Pasetti, LA.; Leão, MTC, Araki, LT. Odontologia Hospitalar - A Importância do Cirurgião-Dentista na Unidade de Terapia Intensiva, Rev.Odontologia (ATO), Bauru, SP., v. 13, n. 4, p. 210-26, abr., 2013.

18. Pizzo, G., Guiglia, R., Lo Russo, L.Dentistry and internal medicine: from the focal infection theory to the periodontal medicine concept. Eur. J. Intern. Med. 21 (6): 496-502, 2010.

19. Queluz, D. P., Palumbro, A. Integração do odontólogo no serviço de saúde em uma equipe multidisciplinar. JAO. 3 (19): 40-6, 2000.

20. Raya, S., Bezerra, A. C. B. Hospitalar pedodontics: treatmentunder general anaesthesia. RGO; 45: 140-4, 1997.

21. Schubert, M.M.; Santos, P.S.S; Soares, L.A.V.J. A prática na odontologia hospitalar. MedicinaBucal. 1-2, pag. 3-20, 2012.

22. Senpuku, H., Sogame, A., Inoshita, E. Systemic diseases in association with microbial species in oral biofilm from elderly requiring care. Gerontology; 49 (5): 301-9, 2003.

23. Souza A.F., Guimarães A.C., Ferreira E.F. Avaliação da implementaçãode novo protocolo de higiene bucal em um centro de terapia intensiva para prevenção de pneumonia associada à ventilação mecânica. REME, Rev.Min. Enferm., v. 17, n. 1, p. 177-84, jan.,/mar., 2013.

24. Stevão, E. L. L. Odontologia Hospitalar. Acesso em: 15/06/2011. Disponível em: http://issuu.com/eberstevao/docs/ odontologia_hospitalar. 